\title{
Effect of literacy on neuropsychological test performance in nondemented, education-matched elders
}

\author{
JENNIFER J. MANLY, ${ }^{1,3,4}$ DIANE M. JACOBS, ${ }^{1,3,4}$ MARY SANO, ${ }^{1,3,4}$ KAREN BELL, ${ }^{1,3,4}$ \\ CAROL A. MERCHANT, ${ }^{1,3,4}$ SCOTT A. SMALL, ${ }^{1,3,4}$ AND YAAKOV STERN, $, 2,3,4$ \\ Departments of ${ }^{1}$ Neurology and ${ }^{2}$ Psychiatry, ${ }^{3}$ the Gertrude H. Sergievsky Center, and ${ }^{4}$ the Taub Center for Alzheimer's Disease \\ Research in the City of New York, Columbia University College of Physicians and Surgeons, New York, NY
}

(Received November 19, 1997; Revised April 22, 1998; Accepted May 28, 1998)

\begin{abstract}
The current investigation compared neuropsychological test performance among nondemented literate and illiterate elders. The sample included participants in an epidemiological study of normal aging and dementia in the Northern Manhattan community. All participants were diagnosed as nondemented by a neurologist, and did not have history of Parkinson's disease, stroke, or head injury. Literacy level was determined by self-report. MANOVAs revealed a significant overall effect for literacy status (literate $v s$. illiterate) on neuropsychological test performance when groups were matched on years of education. The overall effect of literacy status remained significant after restricting the analyses to elders with no formal education, and after controlling for the effects of language of test administration. Specifically, illiterates obtained lower scores on measures of naming, comprehension, verbal abstraction, orientation, and figure matching and recognition. However, tests of verbal list delayed recall, nonverbal abstraction, and category fluency were unaffected by literacy status, suggesting that these measures can be used to accurately detect cognitive decline among illiterate elders in this sample. Differences in organization of visuospatial information, lack of previous exposure to stimuli, and difficulties with interpretation of the logical functions of language are possible factors that contribute to our findings. (JINS, 1999, 5, 191-202.)
\end{abstract}

Keywords: Literacy, Neuropsychological testing, Nondemented elders

\section{INTRODUCTION}

People 65 years of age and older had fewer opportunities to receive formal education. In 1989, the illiteracy rate in the United States was $1.4 \%$ among people 65 and over, almost 5 times higher than the rate for those age 25 to 44 (UNESCO, 1997). A National Adult Literacy Survey (Kirsch et al., 1993) found that one-third of the 21 to $23 \%$ of American adults who performed at the lowest level of a literacy assessment were age 65 and older. Lack of opportunity to attend school has more dramatic effects on literacy rates in less developed countries. As an example, the illiteracy rate in the Dominican Republic among those age 65 and older was $61 \%$ in 1981, also considerably higher than younger Dominicans (22\%; ages 25-34; UNESCO, 1997).

Presence of poor literacy skills among elders is a particularly relevant issue for neuropsychologists attempting to accurately detect dementia using cognitive measures. Weiss and his colleagues (Weiss et al., 1995b) found that reading

Reprint requests to: Yaakov Stern, Gertrude H. Sergievsky Center, 630 West 168th Street, New York, NY 10032-3702. E-mail: sternya@ sergievsky. cpmc.columbia.edu level (as measured by a bilingual measure of reading comprehension) was more related to MMSE score than were years of education, age, or ethnicity. The authors concluded that interpretation of MMSE performance, and therefore accurate assessment of cognitive dysfunction among elders, is dependent on knowledge of literacy or reading skill.

The importance of taking educational attainment into account when interpreting scores on cognitive measures is well established (Heaton et al., 1986; Kittner et al., 1997; Wechsler, 1997). However, distinguishing test bias against those with low educational attainment from actual cognitive impairment is a difficult process, and is highlighted by the current controversy regarding the concept of "cognitive reserve" (Berkman, 1986; Friedland, 1993; Gurland, 1981; Katzman et al., 1988, 1993; Mortimer, 1988; Satz, 1993). Several researchers have suggested that education and/or literacy could provide a protective reserve against clinical manifestations of cerebral neuropathology (Bonaiuto et al., 1990; Dartigues et al., 1991; Evans et al., 1993; Fratiglioni et al., 1991; Korczyn et al., 1991; Rocca et al., 1991; Stern et al., 1992a, 1992c, 1995; Zhang et al., 1990). However, differential ability of cognitive measures to accurately detect neuropathology among individuals with very low and very high levels 
of education has not yet been ruled out as a possible explanation for these findings.

For example, studies of elders in Shanghai (Katzman et al., 1988; Zhang et al., 1990) found that the prevalence of dementia was highest among those with no formal education. The authors acknowledged the possibility that bias against those with low education/illiteracy could have existed for some of the cognitive measures, in the form of unfamiliarity with the procedures used and discomfort or poor motivation during the testing session. However, the authors also suggested that lack of formal education could lower brain reserve against the neuropathology of dementia, allowing the clinical symptoms of dementia to present themselves earlier. Education and/or literacy could also be a surrogate for nutritional, environmental, or economic factors that may lower reserve and thus increase the risk for dementia. This issue becomes more complex in the United States, where there is more discordance between educational attainment and literacy (Kirsch et al., 1993; Weiss et al., 1995a), in part due to the poor quality of education offered to poor, rural, and minority children.

Research interest in the effects of literacy on cognition began when Vygotsky $(1962,1978)$ suggested that the development and organization of basic psychological processes such as abstraction, inference, and memory depended on the type of symbols (e.g., writing systems) used by the individual in their environment. Luria (1976) found that illiterate, unschooled individuals solved cognitive problems in a context-bound manner and were more influenced by the perceptual and functional attributes of a stimulus than were schooled literates, who were more responsive to abstract concepts and logical relationships among stimuli. As a result of their studies of the Vai people in Liberia, Scribner and Cole (1981) concluded that although literacy is not necessary for the development of logic, abstraction, memory, and communication skills, the nature of writing systems and the way in which they are used affect the organization and expression of these cognitive abilities.

Recently, Reis and Castro-Caldas (1997) reported that illiterate women from Southern Portugal performed worse than literate women on repetition of pseudowords, recall of phonologically related word associates, and a fluency task involving generation of words beginning with specific phonemes. The authors concluded that the illiterates' lack of grapheme-phoneme correspondence explained their performance on the language tasks, since all participants shared the same sociocultural environment and differed only on literacy level and some years of formal schooling. Poorly developed phonemic strategies may explain the findings of Lecours and his colleagues (Lecours et al., 1987), who reported that illiterates performed significantly worse than literates on measures of repetition and auditory comprehension.

Discrepancies in the cognitive test performance of literates and illiterates may not be restricted to tasks involving phonemic skills. Two studies (Ardila et al., 1989; Rosselli et al., 1990) compared illiterate individuals to highly edu- cated professionals in Bogota, Colombia. Illiterates performed significantly worse on measures of memory (word list, delayed sentence recall, immediate and delayed short story recall, and figure recall), visuospatial ability (copy of simple and complex figures, time-telling, recognition of superimposed figures), digit span, naming, calculation, praxis, alternating movements, and cancellation tasks. Reis et al. (1994) found that illiterate and semiliterate Portuguese adults had difficulty on visual naming tasks when the objects were presented through line drawings and photographs, but not real objects. Matute et al. (1997) reported that Spanishspeaking illiterates made more errors of rotation and disarticulation (overlapping, distant, or displaced vertices) when assembling stick constructions, which are supposedly more valid for use among illiterates who have little experience with writing utensils.

There is also some evidence that literacy level affects the cerebral organization of language, as evidenced in studies of brain damaged individuals. Lecours and his colleagues (Lecours et al., 1988) found that, among those with righthemisphere damage, illiterates performed worse than literates on measures of naming and had more qualitative errors in their speech (such as phonemic paraphasias, decreased speech output, and word-finding difficulties). The authors concluded that although the left hemisphere is dominant for language regardless of literacy level, the cerebral organization of language is less lateralized among illiterates.

Taken together, the results of prior research suggest that literacy level has a significant influence on the nature of performance on traditional neuropsychological measures of verbal and nonverbal skills; however, many studies were unable to distinguish between the effects of literacy and the effects of little or no exposure to formal education. The purpose of the current investigation was to compare the test performance of nondemented literate and illiterate elders on a dementia battery. We wondered which measures in our neuropsychological battery were most affected by literacy status, and therefore would have decreased utility for the assessment of dementia among illiterate elders. Conversely, we investigated whether our battery contained any measures which were insensitive to literacy level, and could therefore reliably detect cognitive impairment regardless of literacy status. Our study was unique in that we were able to distinguish the effects of literacy alone versus those associated with formal education, since in addition to those who never learned to read and write, there were many elders in our sample who were literate but received little or no formal education.

We hypothesized that illiterate elders would obtain lower scores on tests of verbal list learning and recall, language (naming, fluency, comprehension, and repetition), drawing, and verbal abstraction than education-matched literate elders. However, we did not expect differences between literate and illiterate groups on measures of orientation, nonverbal abstraction, and figure matching-recognition, since these tests assessed basic cognitive abilities without requiring the use of phonemic or writing skills. 


\section{METHOD}

\section{Research Participants}

The current sample was selected from participants in the Washington Heights Inwood Columbia Aging Project (WHICAP), a community-based, epidemiological study of dementia in the ethnically diverse neighborhoods of Northern Manhattan, New York. The WHICAP study follows a random sample of elderly Medicare recipients residing in selected census tracts of Washington Heights and Inwood. The population from which participants were drawn is comprised of individuals from several different countries of origin and representing three broadly defined ethnic categories (i.e., Hispanic, African American, and White). Approximately $6.5 \%$ of the overall cohort reports that they are illiterate.

\section{Inclusion-exclusion criteria}

All potential participants were age 65 and above and reported having zero to 3 years of education. Participants were excluded if they had a history of Parkinson's disease, stroke, or alcohol abuse. Only WHICAP participants who showed no neurological or functional signs of delirium or dementia were included in the current analyses. This determination was made on the basis of a neurologist's clinical examination (theoretically less influenced by literacy level).

Medical evaluation. A neurologist recorded medical history and medications in a semistructured format. Neurological and brief physical examinations were performed, including assessment of extrapyramidal signs. Functional status was measured using Part 1 of the Blessed Dementia Rating Scale (BDRS; Blessed et al., 1968) and the Schwab and England rating scale of activities of daily living (Boller et al., 1980), and cognition was formally assessed using the short version of the Blessed Memory Information and Concentration Test (Katzman et al., 1983). From this information, the neurologist determined whether the participant met criteria for delirium or dementia using Diagnostic and Statistical Manual of Mental Disorders-Revised Third Edition (American Psychiatric Association, 1987) criteria. Interviews were conducted in English or Spanish, according to the participant's wishes.

\section{Sample characteristics}

A total of 251 WHICAP participants had neuropsychological evaluations, literacy data, neurological exams, and no more than 3 years of education. Of these, $36 \%$ reported being illiterate. We chose 3 years of education as a cut-off because (1) we did not want to confound lack of opportunity for schooling with learning disability, and (2) $89 \%$ of the illiterates in the cohort fell within this range of education. Of the participants with zero to 3 years of education, $1.6 \%$ $(N=4)$ were excluded due to Parkinson's disease, $1.2 \%$
$(N=3)$ had history of a stroke, and one had history of alcohol abuse. One participant was excluded due to diagnosis of delirium, and $24 \%$ were diagnosed with dementia $(N=$ 59). Approximately $29 \%$ of the illiterates within this education range were eliminated due to presence of dementia, which was statistically equivalent to that of the literate group $\left(21 \% ; \chi^{2}(1)=2.12, p>.05\right)$. A sample of 187 (123 literate and 64 illiterate) elders remained after applying the criteria above.

\section{Procedure}

\section{Neuropsychological battery}

The neuropsychological measures used in the current study were selected to assess cognitive functions that are typically affected in dementia and has been shown to effectively distinguish between normal aging and dementia in this community (Stern et al., 1992b). The evaluation included measures of learning and memory, orientation, abstract reasoning, language, and visuospatial ability. Specific ability areas and tests administered include verbal list learning and memory [Selective Reminding Test (SRT); Buschke $\&$ Fuld, 1974], nonverbal memory [multiple choice version of the Benton Visual Retention Test (BVRT); Benton, 1955], orientation [items from the Mini Mental State Examination (MMSE); Folstein et al., 1975], verbal reasoning [Similarities subtest of the Wechsler Adult Intelligence ScaleRevised (WAIS-R); Wechsler, 1981] nonverbal reasoning (Identities and Oddities subtest of the Mattis Dementia Rating Scale; Mattis, 1976), naming (15-item version of the Boston Naming Test; Kaplan et al., 1983), letter fluency (Controlled Word Association; Benton \& Hamsher, 1976; Jacobs et al., 1997), category fluency [animals, food, and clothing, using procedures from the Boston Diagnostic Aphasia Examination (BDAE); Goodglass \& Kaplan, 1983], repetition (high-frequency phrases of the BDAE; Goodglass \& Kaplan, 1983), auditory comprehension (first six items of the Complex Ideational Material subtest of the BDAE; Goodglass \& Kaplan, 1983), visuoconstruction (Rosen Drawing Test; Rosen, 1981), and visuoperceptual skills (multiple choice matching of figures from the BVRT; Benton, 1955).

All interview questions, test instructions, and stimuli were translated into Spanish by a committee of Spanish speakers from Cuba, Puerto Rico, Spain, and the Dominican Republic, and then back-translated to ensure accuracy. Test items were translated literally. Where necessary, scoring criteria were modified so as to give credit for responses reflecting regional idioms. The Spanish version of the battery is described in detail elsewhere (Jacobs et al., 1997).

Evaluations were conducted in either English or Spanish, based on the participant's opinion of which language would yield the best performance. Examiners were balanced bilinguals, who spoke both English and Spanish daily with friends, family, and colleagues.

The letter fluency test was difficult or impossible for most of our illiterate participants. Letter fluency was coded as 
missing if participants were unable or refused to perform the letter fluency task.

\section{Literacy}

At the time of the neuropsychological evaluation, each participant was asked: "Did you ever learn to read and write?" as a part of a survey questionnaire. Generally, illiterate elders in the study were born and raised in rural communities in the Caribbean or the southern United States, where formal schooling was unavailable or they were required to work at an early age. When these individuals came to New York City, they usually obtained jobs that did not require reading or writing skills, and many of the women worked as housewives. Literates with no formal education usually learned to read and write from siblings at home.

\section{Statistical Methods}

Three samples of participants were used in our statistical analyses:

1. Stratified random sample: Although the sample was restricted to elders with zero to 3 years of formal education, the majority of illiterates had no formal education, while the majority of literates had 3 years of education. In order to create groups matched on educational status, a stratified random sampling method was applied. The sample was stratified by literacy status (literate, illiterate) and years of education $(0,1,2$, or 3 years). Within each Literacy $\times$ Education cell, a random sample of participants was selected using the SPSS (1993) sample function. Equal numbers of participants were selected within each Literacy $\times$ Education stratum.

2. Uneducated sample: Literates and illiterates with no formal education were selected from the original sample of 187 nondemented elders for a separate set of analyses.

3. Spanish-speakers only: Stratified random and uneducated samples of only those who performed the neuropsychological battery in Spanish were selected from the original sample of 187 nondemented elders in order to assess the effect of literacy while controlling for the effects of language.

\section{Statistical analyses}

Within each sample, ANOVAs were performed to compare literates and illiterates on age and functional status (Schwab and England and BDRS functional scales). Chi-square analyses were used to compare the proportion of women and Spanish-speakers in each group. We also compared the proportion of participants within each group who were able to complete the letter fluency task.

The overall neuropsychological test performance of education-matched literates and illiterates was compared using a $2 \times 2$ MANOVA, which assessed for the unique contribution of literacy level (literate $v s$. illiterate) with lan- guage (English vs. Spanish) accounted for. Twelve measures from the test battery were included as dependent variables: total raw scores for immediate recall and delayed recall from the SRT; BVRT matching and recognition memory; 15-item Boston Naming; BDAE repetition; BDAE comprehension; Mattis Identities and Oddities; MMSE Orientation; number correct on the Rosen Drawing Test; agecorrected scaled score on WAIS-R Similarities; and mean number of words generated over three 60-s trials for category fluency. Post-hoc 2 (literate vs. illiterate) $\times 2$ (English vs. Spanish) ANOVAs were performed to determine which specific neuropsychological measures contributed significantly to the overall multivariate effect. In order to strike a balance between the likelihood of committing Type I and Type II errors, an alpha level of $p<.01$ was used to determine statistically significant univariate differences.

The analyses described above were repeated for the stratified random sample of uneducated literates and illiterates. In addition, we performed a MANOVA and post-hoc ANOVAs to assess the effect of literacy (illiterate vs. literate) on neuropsychological test scores among the Spanishspeaking stratified random and uneducated samples.

\section{Secondary analyses}

Because literacy level was determined by self-report, we needed to address the possibility that some elders might be embarrassed to admit their illiteracy, and thus be inappropriately included in the literate group. In a set of secondary analyses, we used performance on the letter fluency task to address this issue in two ways. First, we determined if selfreported literates who did not perform the letter fluency task were different on demographic and neuropsychological variables than self-reported literates who did perform the letter fluency task. ANOVAs were used to compare self-reported literates who performed the letter fluency task to those who did not perform the task on age, years of education, years in the United States, and functional variables. Using MANOVA, we assessed the effect of letter fluency status (attempted vs. not attempted) on the 12 measures from the neuropsychological test battery within those who reported that they could read and write. The second strategy determined if limiting the literate group to only those who performed the letter fluency task altered the outcome of our analyses. After eliminating those self-reported literates who did not perform the letter fluency task from the original sample, we reformed our stratified random and uneducated samples, and performed the analyses described above again using the new samples.

\section{RESULTS}

\section{Stratified Random Sample}

Groups of 43 literate and 43 illiterate elders matched on educational attainment were formed through the stratified random sampling procedure described above. Of this sample, 
$67 \%$ reported their birthplace as the Dominican Republic, $14 \%$ were born in the U.S., $7 \%$ in Cuba, $5 \%$ in Puerto Rico, and $7 \%$ in other countries. There was no difference in rates of literacy by country of birth. Literates had an average age of $76.2(S D=6.1)$, statistically equivalent to the illiterate group $[M=74.8, S D=5.7 ; F(1,84)=1.19, p>.05]$. Both groups were $74 \%$ female, and the proportion of Spanishspeakers in the literate $(72 \%)$ and illiterate $(86 \%)$ groups were not statistically different $\left[\chi^{2}(1)=2.57, \mathrm{p}=.11\right]$. The literate group was $81 \%$ Hispanic, $9 \%$ African American, and $10 \%$ non-Hispanic White, and the illiterate group was $91 \%$ Hispanic and 9\% African American.

The groups were equivalent on measures of daily functioning, including the Schwab and England $[F(1,50)=0.10$, $p>.05]$ and the BDRS functional score $[F(1,50)=0.41$, $p>.05]$. On average, the literate group was $85 \%$ independent, and the illiterate group was functioning at $87 \%$ independence.

As expected, many of those who identified themselves as illiterate could not perform the letter fluency task (47\%), whereas $16 \%$ of the literate group did not perform the task $\left[\chi^{2}(1)=9.42, p=.002\right]$. Illiterates who did attempt the task generated on average three words per trial, significantly less than the literate group's average of six words per trial $[F(1,57)=9.8, p<.003]$.

A $2 \times 2$ MANOVA revealed significant overall effects of both language $[F(12,60)=2.74, p=.005]$ and literacy $[F(12,60)=2.22, p=.022]$ with no significant interaction effect. However, follow-up univariate analyses revealed that the effect of language on neuropsychological test score was not significant below the .01 level for any individual measure. As seen in Table 1, literates obtained significantly higher scores than education-matched illiterates on SRT total recall, WAIS-R Similarities, BDAE Comprehension, and BVRT matching, even with the effect of language accounted for. Illiterates also obtained lower scores than literates on BVRT recognition; however, this difference did not quite meet our $p<.01$ criterion.

\section{Uneducated Sample}

This sample consisted of 26 literates and 47 illiterates with no formal education. The two groups were equivalent on age $[F(1,71)=0.84, p>.05]$ and functional status as measured by the Schwab and England $[F(1,39)=0.02, p>$ $.05]$ and the BDRS functional scale $[F(1,39)=1.55, p>$ $.05]$. There were equal proportions of women in each group $\left[\chi^{2}(1)=1.04, \mathrm{p}>.05\right]$. However, there was a higher proportion of Spanish-speakers in the illiterate group (92\%) as compared to the literate group $\left[65 \% ; \chi^{2}(1)=7.5, \mathrm{p}=.006\right]$. Significantly more illiterates $(66 \%)$ did not perform the letter fluency task as compared to literates $\left[19 \% ; \chi^{2}(1)=15.44\right.$, $\mathrm{p}<.000]$.

A $2 \times 2$ MANOVA revealed significant effects of both language $[F(12,45)=2.43, p=.016]$ and literacy $[F(12,45)=2.12, p=.035]$ on overall test performance, with no significant interaction effect. Univariate testing showed that, independent of language, illiterates obtained

Table 1. Cognitive test scores of literate $(N=43)$ and illiterate $(N=43)$ education matched elders

\begin{tabular}{|c|c|c|c|c|c|c|}
\hline \multirow[b]{2}{*}{ Test } & \multicolumn{2}{|c|}{ Literate } & \multicolumn{2}{|c|}{ Illiterate } & \multicolumn{2}{|c|}{ Effect of literacy ${ }^{\mathrm{a}}$} \\
\hline & $M$ & $(S D)$ & $(M)$ & $(S D)$ & $F$ & $p$ \\
\hline \multicolumn{7}{|l|}{ Learning-Memory } \\
\hline SRT total recall & 34.65 & $(11.53)$ & 29.37 & $(7.05)$ & 9.68 & .003 \\
\hline SRT delayed recall & 4.86 & $(2.85)$ & 4.02 & $(1.90)$ & 3.07 & .083 \\
\hline BVRT recognition memory & 5.12 & $(2.35)$ & 3.75 & $(1.75)$ & 6.24 & .015 \\
\hline \multicolumn{7}{|l|}{ Orientation } \\
\hline MMSE orientation & 9.33 & $(.89)$ & 8.60 & $(1.45)$ & 4.73 & .033 \\
\hline \multicolumn{7}{|l|}{ Abstract reasoning } \\
\hline WAIS-R Similarities & 6.65 & $(2.94)$ & 5.30 & $(1.30)$ & 10.39 & .002 \\
\hline DRS Identities \& Oddities & 12.61 & $(2.80)$ & 12.46 & $(2.28)$ & .009 & .924 \\
\hline \multicolumn{7}{|l|}{ Language } \\
\hline Boston Naming & 12.76 & $(1.40)$ & 11.33 & $(2.29)$ & 4.98 & .029 \\
\hline Category fluency & 11.79 & $(3.97)$ & 11.55 & $(3.14)$ & 1.02 & .315 \\
\hline BDAE repetition & 7.49 & $(.91)$ & 7.26 & $(1.11)$ & 2.83 & .097 \\
\hline BDAE Comprehension & 4.36 & $(1.50)$ & 3.30 & $(1.24)$ & 8.14 & .006 \\
\hline \multicolumn{7}{|l|}{ Visuospatial ability } \\
\hline Rosen Drawing & 1.58 & $(1.11)$ & 1.02 & $(.94)$ & 2.22 & .141 \\
\hline BVRT matching & 6.58 & $(2.16)$ & 5.35 & $(2.25)$ & 9.36 & .003 \\
\hline
\end{tabular}

Note. SRT $=$ Selective Reminding Test $;$ BVRT $=$ Benton Visual Retention Test MMSE $=$ Mini-Mental State Examination; WAIS-R = Wechsler Adult Intelligence Scale-Revised; DRS = Dementia Rating Scale; BDAE = Boston Diagnostic Aphasia Examination.

${ }^{\mathrm{a}}$ The effect of literacy (literate $v s$. illiterate) on neuropsychological test score after the effect of language (English $v s$. Spanish) is accounted for using $2 \times 2$ ANOVA. 
significantly lower scores on BVRT recognition memory, WAIS-R Similarities, BDAE Repetition, and BVRT matching than literates (Table 2). There were no significant effects of language on individual test scores.

\section{Spanish-Speaking Stratified Random Sample}

After restricting potential participants to those who performed the neuropsychological battery in Spanish, we selected groups of 32 literate and 32 illiterate elders using the stratified random sampling procedure described above. Literates and illiterates were comparable on age $[F(1,62)=0.15, p>.05]$, functional status [Schwab \& England, $F(1,39)=1.78, p>$ $.05]$; BDRS functional scale $[F(1,39)=0.07, p>.05]$, and proportion of women in each group $\left[\chi^{2}(1)=0.37, p>.05\right]$. Significantly more illiterates did not perform the letter fluency task than the literate group, as expected $\left[\chi^{2}(1)=5.61\right.$, $p=.02]$.

MANOVA revealed a significant effect of literacy level on overall neuropsychological test performance $[F(1,41)=2.24, p=.028]$, and follow-up univariate testing showed that illiterates scored significantly lower than literates on Boston Naming, BDAE Comprehension, and BVRT matching (Table 3).

\section{Spanish-Speaking Uneducated Sample}

We further restricted the sample to only those Spanishspeakers with no formal education. A sample of 17 literates and 43 illiterates were selected; the groups were equivalent on age $[F(1,58)=0.45, p>.05]$, functional status $[F(1,33)=0.00, p>.05]$, and proportion of female participants $\left[\chi^{2}(1)=0.05, p>.05\right]$. Again, significantly more illiterates did not perform the letter fluency task as compared to literates $\left[\chi^{2}(1)=7.24, p=.007\right]$.

MANOVA showed a significant effect of literacy status on overall neuropsychological test performance among Spanish-speakers with no formal education $[F(12,34)=2.59$, $p=.015]$. Follow-up univariate testing showed that illiterates scored lower than literates on BVRT matching, although this difference only approached our $p<.01$ significance criterion (Table 4).

\section{Secondary Analyses}

It is possible that the $16 \%$ of self-reported literates in the stratified random sample who did not perform the letter fluency task were in fact illiterates who were not willing to admit their literacy status. We addressed this concern by comparing demographic variables and neuropsychological test performance of those self-reported literates who performed the letter fluency task $(N=36)$ to literates who did not perform the task $(N=7)$. ANOVAs showed that the groups did not significantly differ in terms of age, years of education, years in the United States, or functional variables $(p>.05$ for all). Most importantly, a MANOVA revealed that there was no overall effect of letter fluency status (attempted $v s$. not attempted) on the remaining neuropsychological test

Table 2. Cognitive test scores of literate $(N=26)$ and illiterate $(N=47)$ elders with no formal education

\begin{tabular}{|c|c|c|c|c|c|c|}
\hline \multirow[b]{2}{*}{ Test } & \multicolumn{2}{|c|}{ Literate } & \multicolumn{2}{|c|}{ Illiterate } & \multicolumn{2}{|c|}{ Effect of literacy ${ }^{\mathrm{a}}$} \\
\hline & $M$ & $(S D)$ & $M$ & $(S D)$ & $F$ & $p$ \\
\hline \multicolumn{7}{|l|}{ Learning-Memory } \\
\hline SRT total recall & 32.08 & $(10.90)$ & 28.11 & $(7.29)$ & 5.06 & .028 \\
\hline SRT delayed recall & 4.31 & (2.69) & 3.57 & $(1.92)$ & 3.26 & .076 \\
\hline BVRT recognition memory & 4.96 & $(2.40)$ & 3.47 & $(1.72)$ & 8.06 & .006 \\
\hline \multicolumn{7}{|l|}{ Orientation } \\
\hline MMSE orientation & 9.32 & $(.90)$ & 8.44 & $(1.52)$ & 4.83 & .031 \\
\hline \multicolumn{7}{|l|}{ Abstract reasoning } \\
\hline WAIS-R Similarities & 7.04 & $(3.25)$ & 5.33 & $(1.57)$ & 10.27 & .002 \\
\hline DRS Identities \& Oddities & 12.22 & $(3.16)$ & 12.77 & $(2.04)$ & .238 & .627 \\
\hline \multicolumn{7}{|l|}{ Language } \\
\hline Boston Naming & 12.74 & $(1.54)$ & 11.24 & $(2.50)$ & 4.89 & .031 \\
\hline Category fluency & 11.34 & $(3.48)$ & 12.15 & (3.07) & .283 & .596 \\
\hline BDAE repetition & 7.58 & $(.83)$ & 7.11 & $(1.15)$ & 7.56 & .008 \\
\hline BDAE Comprehension & 4.54 & $(1.38)$ & 3.43 & $(1.39)$ & 3.47 & .067 \\
\hline \multicolumn{7}{|l|}{ Visuospatial ability } \\
\hline Rosen Drawing & 1.48 & $(1.04)$ & .88 & $(.88)$ & 4.96 & .030 \\
\hline BVRT matching & 6.52 & $(2.23)$ & 4.79 & $(1.93)$ & 16.98 & .000 \\
\hline
\end{tabular}

Note. SRT $=$ Selective Reminding Test BVRT $=$ Benton Visual Retention Test MMSE $=$ Mini-Mental State Examination; WAIS $-\mathrm{R}=$ Wechsler Adult Intelligence Scale-Revised; DRS = Dementia Rating Scale; $\mathrm{BDAE}=$ Boston Diagnostic Aphasia Examination .

${ }^{\text {a }}$ The effect of literacy (literate $v s$. illiterate) on neuropsychological test score after the effect of language

(English $v s$. Spanish) is accounted for using $2 \times 2$ ANOVA. 
Table 3. Cognitive test scores of Spanish-speaking literate $(N=32)$ and illiterate $(N=32)$ education-matched elders

\begin{tabular}{|c|c|c|c|c|c|c|}
\hline \multirow[b]{2}{*}{ Test } & \multicolumn{2}{|c|}{ Literate } & \multicolumn{2}{|c|}{ Illiterate } & \multicolumn{2}{|c|}{ Effect of literacy } \\
\hline & $M$ & $(S D)$ & $(M)$ & $(S D)$ & $F$ & $p$ \\
\hline \multicolumn{7}{|l|}{ Learning-Memory } \\
\hline SRT total recall & 33.38 & $(10.28)$ & 28.78 & $(7.13)$ & 4.32 & .042 \\
\hline SRT delayed recall & 4.53 & $(2.38)$ & 3.75 & $(2.05)$ & 1.98 & .165 \\
\hline BVRT recognition memory & 5.10 & $(2.14)$ & 3.97 & $(1.72)$ & 5.20 & .020 \\
\hline \multicolumn{7}{|l|}{ Orientation } \\
\hline MMSE orientation & 9.10 & $(.98)$ & 8.59 & $(1.43)$ & 2.58 & .114 \\
\hline \multicolumn{7}{|l|}{ Abstract reasoning } \\
\hline WAIS-R Similarities & 5.69 & $(1.69)$ & 5.31 & $(1.60)$ & .803 & .374 \\
\hline DRS Identities \& Oddities & 12.11 & $(2.90)$ & 12.29 & $(2.58)$ & .062 & .804 \\
\hline \multicolumn{7}{|l|}{ Language } \\
\hline Boston Naming & 12.89 & $(1.22)$ & 10.94 & $(2.58)$ & 12.93 & .001 \\
\hline Category fluency & 10.88 & $(3.90)$ & 11.59 & $(3.21)$ & .609 & .438 \\
\hline BDAE repetition & 7.57 & $(.84)$ & 7.16 & $(1.13)$ & 2.47 & .121 \\
\hline BDAE Comprehension & 4.18 & $(1.25)$ & 3.06 & $(1.24)$ & 11.83 & .001 \\
\hline \multicolumn{7}{|l|}{ Visuospatial ability } \\
\hline Rosen Drawing & 1.30 & $(1.03)$ & .97 & $(1.00)$ & 1.50 & .226 \\
\hline BVRT matching & 6.83 & $(2.02)$ & 5.16 & $(2.05)$ & 10.04 & .002 \\
\hline
\end{tabular}

Note. SRT $=$ Selective Reminding Test BVRT $=$ Benton Visual Retention Test; MMSE $=$ Mini-Mental State Examination; WAIS-R = Wechsler Adult Intelligence Scale-Revised; DRS = Dementia Rating Scale; BDAE $=$ Boston Diagnostic Aphasia Examination.

${ }^{a}$ The effect of literacy (literate $v s$. illiterate) on neuropsychological test score using ANOVA.

scores $[F(13,24)=1.75, p>.05]$ among self-reported literates. However, these results may reflect low power due to the small number of "no-letter fluency literates"; therefore, we repeated these analyses in the larger sample of self- reported literates $(N=123)$. We found that the no-letter fluency literates $(N=11)$ did not significantly differ from the literates who performed the task $(N=112)$ in terms of age, years in the U.S., functional variables, and the other neuro-

Table 4. Cognitive test scores of Spanish-speaking literate $(N=17)$ and illiterate $(N=43)$ elders with no formal education

\begin{tabular}{|c|c|c|c|c|c|c|}
\hline \multirow[b]{2}{*}{ Test } & \multicolumn{2}{|c|}{ Literate } & \multicolumn{2}{|c|}{ Illiterate } & \multicolumn{2}{|c|}{ Effect of literacy ${ }^{a}$} \\
\hline & $M$ & $(S D)$ & $(M)$ & $(S D)$ & $F$ & $p$ \\
\hline \multicolumn{7}{|l|}{ Learning-Memory } \\
\hline SRT total recall & 32.00 & $(10.37)$ & 28.63 & $(7.39)$ & 2.00 & .163 \\
\hline SRT delayed recall & 4.29 & $(2.37)$ & 3.70 & $(1.91)$ & 1.04 & .313 \\
\hline BVRT recognition memory & 4.67 & $(2.23)$ & 3.54 & $(1.70)$ & 4.01 & .051 \\
\hline \multicolumn{7}{|l|}{ Orientation } \\
\hline MMSE orientation & 9.00 & $(.97)$ & 8.44 & $(1.52)$ & 1.88 & .176 \\
\hline \multicolumn{7}{|l|}{ Abstract reasoning } \\
\hline WAIS-R Similarities & 6.06 & $(1.65)$ & 5.39 & $(1.61)$ & 1.98 & .165 \\
\hline DRS Identities \& Oddities & 11.29 & $(3.47)$ & 12.75 & (2.11) & 3.50 & .067 \\
\hline \multicolumn{7}{|l|}{ Language } \\
\hline Boston Naming & 12.86 & $(1.41)$ & 11.29 & $(2.61)$ & 4.54 & .038 \\
\hline Category fluency & 10.51 & $(3.06)$ & 12.38 & $(3.02)$ & 4.36 & .041 \\
\hline BDAE repetition & 7.67 & $(.82)$ & 7.23 & $(1.05)$ & 2.16 & .148 \\
\hline BDAE Comprehension & 4.20 & $(1.32)$ & 3.35 & $(1.41)$ & 4.12 & .048 \\
\hline \multicolumn{7}{|l|}{ Visuospatial ability } \\
\hline Rosen Drawing & 1.29 & $(.99)$ & .90 & $(.88)$ & 1.87 & .178 \\
\hline BVRT matching & 6.50 & $(2.03)$ & 5.03 & $(1.80)$ & 6.47 & .014 \\
\hline
\end{tabular}

Note. SRT $=$ Selective Reminding Test BVRT $=$ Benton Visual Retention Test; MMSE $=$ Mini-Mental State Examination; WAIS-R = Wechsler Adult Intelligence Scale-Revised; DRS = Dementia Rating Scale; BDAE = Boston Diagnostic Aphasia Examination.

${ }^{a}$ The effect of literacy (literate $v s$. illiterate) on neuropsychological test score using ANOVA. 
psychological measures. However, as expected in this nonmatched sample, literates who performed the letter fluency task had significantly more years of education $(M=0.69$, $S D=0.89)$ than those who did not perform the task $[M=$ $0.20, S D=0.58 ; F(1,62)=6.97, p=.01]$.

In a second step, all analyses were repeated after restricting the literate group to only those who performed the letter fluency task. After eliminating from the original sample $(N=187)$ self-reported literates who did not perform letter fluency (new $N=176$ ), we repeated the stratified random sampling procedures to develop samples of educationmatched literates $(N=38)$ and illiterates $(N=38)$, and education matched Spanish-speaking literates $(N=25)$ and illiterates $(N=25)$. Uneducated and Spanish-speaking uneducated samples were also drawn from the revised larger sample. The results of these analyses reflected the results obtained in the original sample, showing that illiterate elders obtained significantly lower scores on the overall neuropsychological test battery as compared to education-matched literates. Due to the smaller sample sizes, significance levels of some post-hoc ANOVAs that were significant below the $p<.01$ level for the original analyses did not reach this criterion, but most were significant below the $p<.05$ level.

\section{DISCUSSION}

The current study found that overall, illiterates obtained significantly lower neuropsychological test scores than education-matched literates. The overall effect of literacy status remained significant when the analysis was limited to those with no formal schooling and when the potential effect of language of test administration was controlled. A major problem with previous investigations has been that literacy is often confounded with the influence of schooling (Scribner \& Cole, 1981). Because our sample included individuals who had learned to read and write, yet had received little or no schooling, we were able to control for the major environmental influence of formal education and test for the effects of literacy status alone.

Throughout each of our analyses, three measures showed consistent differences between literates and illiterates. First, we found that illiterates obtained significantly lower scores than literates on BVRT matching and recognition. The recognition task consists of the matching task with an added delay component; therefore, group differences on BVRT recognition are most likely due to visuospatial decision making rather than nonverbal memory per se. Perhaps literates have better developed skills in organization and analysis of certain types of visuospatial information than do individuals who have not learned how to read and write. Alternatively, literates may be successfully using linguistic skills to mediate nonverbal tasks, skills that illiterates cannot access. Our group has also found differences between African Americans and Whites (Manly et al., 1998) and between English and Spanish-speakers (Jacobs et al., 1997) on BVRT matching and recognition among groups matched on years of education. It is possible that these ethnic and/or lan- guage group differences are attributable, in part, to group differences in literacy levels that could not be accounted for by years of education.

Differences on our measure of visual naming (15 items from the Boston Naming Test) were expected, and consistent with the findings of three prior investigations of visual naming ability of illiterates (Lecours et al., 1987; Reis et al., 1994; Rosselli et al., 1990). The line drawings may have been more ambiguous or less recognizable for illiterates, thus more difficult to name even with a stimulus cue. Reis and her colleagues (Reis et al., 1994) discuss the possibility that learning conventional representations of familiar objects is comparable to learning representations of letters or words. Additionally, illiterates may have less exposure to, or familiarity with, the objects themselves (e.g., camel, cactus, accordion, harp) as a result of their reading limitations.

Third, we found consistent literacy-related differences on the BDAE Comprehension subtest. It is well established that preliterate children have difficulty understanding that sentences such as "Sam hit John" and "John was hit by Sam" are the same (Scribner \& Cole, 1981). The BDAE Complex Ideational Material subtest used in the current study contains similar reversible sentences (e.g., "Do two pounds of sugar weigh more than one?") which adult illiterates have problems interpreting (Lecours et al., 1987; Rosselli et al., 1990). The construction of written language provides literate individuals with practice in interpretation of complex sentences in which subject-object order is varied, and in decoding logical relationships from language.

We also found that illiterates obtained lower scores than literates on the WAIS-R Similarities subtest and MMSE Orientation, although the power to detect these differences was reduced in the Spanish-speaking samples. As previously described by Luria (1976) and Scribner and Cole (1981), illiterates may have focused on more practical, concrete aspects of the Similarities items or lack the vocabulary to obtain higher scores on the measure. In addition, it is possible that illiterates have more difficulty with items that assess orientation to time because they have no opportunity to read or write the exact date.

Although illiterates did not acquire as many words as literates during the six learning trials of the Selective Reminding Test, the groups did not differ on recall of words after a delay. The Selective Reminding Test (Buschke \& Fuld, 1974) requires participants to learn a list of 12 unrelated words over six trials. After each recall attempt, participants are reminded of only those words that were not successfully recalled. Long-term retention of the list is assessed after a 15min delay using free recall, followed by a multiple-choice recognition task. Our finding that literacy status has no effect on delayed recall is promising for assessing illiterate elders for dementia, since memory dysfunction is a hallmark sign of dementia and rapid forgetting is particularity important for the diagnosis of Alzheimer's disease (e.g., Bondi et al., 1994; Tröster et al., 1993; Welsh et al., 1992). Of course, adequate corrections for years of education must 
be applied, and future research is needed to determine if these results generalize to measures of verbal list learning other than the Selective Reminding Test.

Many illiterates were unable to generate words for the letter fluency task, simply because they are unfamiliar with correspondence between the letters provided and their sounds, as well as word spellings. Those illiterates who did attempt the task scored significantly worse than the education-matched literate group. However, we unexpectedly found that literates and illiterates did not differ on the number of words generated for the category fluency task, in which participants were asked to generate exemplars in the categories of animals, foods, and clothing for $60 \mathrm{~s}$ per category. These results are consistent with Reis and her colleagues (Reis \& Castro-Caldas, 1997) who found that illiterates performed worse on a fluency task that used a "formal," phonological criterion as compared to a semantic (category) fluency task. Again, this finding is encouraging for the accurate assessment of illiterates for dementia, especially since semantic fluency has been found to be disproportionately impaired among those with Alzheimer's disease (e.g., Barr \& Brandt, 1996; Binetti et al., 1995; Monsch et al., 1992, 1997; Tröster et al., 1989).

We restricted our sample to elders with little formal opportunity to attain literacy (no more than 3 years of education), in order to minimize the likelihood that illiterates had specific intellectual deficits that contributed to their inability to read and write, such as subaverage IQ or learning disability. However, we cannot definitively rule out the possibility that differences in overall intellectual abilities can explain not only why literates obtain higher neuropsychological test scores than illiterates, but also why individuals with limited opportunities for formal education learned how to read and write. Nevertheless, some observations from the current study suggest that among this group of elders, intellectual ability is equivalent between literate and illiterate groups. First, although literates perform better than education-matched illiterates on an array of verbal and nonverbal tests, we found that assessments of verbal list memory, nonverbal abstraction and category fluency were unaffected by literacy status. If differences in literacy level were primarily due to differences in general intellectual abilities, all cognitive measures should be affected. Second, although the way in which literacy was attained was not formally assessed, informal discussions with our participants suggest that the opportunity to attain literacy skills may be more related to whether a younger sibling attended school and whether there was an opportunity to learn skills from that sibling. In the future, researchers should carefully identify possible reasons for low literacy, and clarify the ways in which literacy was attained (e.g., formal schooling, learning from siblings, or adult education), especially since educational opportunities have increased since our cohort was of school age.

Interpretation of the results of the current study is limited because literacy was determined by self-report rather than measured directly. The fact that some of the illiterate indi- viduals attempted the letter fluency task suggests that they had some knowledge of grapheme-phoneme correspondence and therefore were not absolute illiterates. Just as there was probably a limited range of reading and writing abilities within our illiterate group, a range of skills within our low-educated literate group is also likely, possibly due to reluctance to admit to illiteracy. We attempted to address variability in our self-reported literate group by (1) determining if there were any differences between the majority of literates who performed the letter fluency task and the minority of literates who did not attempt the task, and (2) repeating our analyses after eliminating literates who did not attempt the letter fluency task. These analyses revealed that there were no significant differences in terms of demographic and cognitive variables between literates who did and did not attempt the letter fluency task, and our findings did not change after eliminating literates who did not perform the task. Nevertheless, for future study, continuous measures of literacy skills such as letter/word identification and reading comprehension tasks would be more reliable and provide more useful information than self-report data alone.

Although our participants were diagnosed as currently nondemented by a neurologist, it is possible that a greater proportion of the illiterates are in the preclinical stages of dementia due to less cognitive reserve, therefore explaining their lower test scores. Snowdon and his colleagues (Snowdon et al., 1996) analyzed the linguistic quality of autobiographies written approximately 58 years earlier by a group of now elderly nuns. Both grammatical complexity and idea density of the autobiographies were associated with cognitive function later in life, and among those who died and in whom Alzheimer's disease was neuropathologically confirmed, $100 \%$ were classified as having low idea density earlier in life. Only longitudinal studies will be able to establish appropriate normative data for illiterate and loweducated individuals, by restricting analyses to those whose cognitive functioning remains stable over time (inconsistent with a dementing process). However, there is some evidence that the normal aging process is different for illiterate elders. Finley and colleagues (Finley et al., 1991) reported that the verbal abilities of normal, nondemented illiterate elders declined more quickly with age as compared to literate and well-educated individuals.

Noncognitive factors could contribute to the findings of the current study. Illiterates may have obtained lower scores than literates because they were more uncomfortable during the testing session, or were less motivated to perform well than the literate individuals. The motivation of an individual who acquired reading and writing skills without the benefit of formal schooling may be inherently greater than the individual who did not acquire literacy skills. However, since the groups were equivalent on many effortful, intimidating tasks such as SRT delay and the category test, this contribution of these factors to group differences is probably minimal.

Literacy involves not only the ability to read and write script, but also the knowledge of how and in what context 
to apply literacy skills for specific purposes. All reading and writing tasks involve specific skills such as encoding language into graphic symbols, the visual and motor abilities involved in forming and decoding characters, words, or sentences, and retrieving word representations from memory (Scribner \& Cole, 1981). Since each of these skills could potentially have an effect on cognitive test performance, future investigations of literacy could measure these specific abilities in order to clarify their relationships to performance on neuropsychological measures.

In addition, the ways in which reading and writing skills are used can also impact the relationship between literacy and cognition. Using an example from Scribner and Cole (1981), if reading and writing skills are used for record keeping, the individual must systematically record information and classify that information into useful categories. On the other hand, if literacy skills are used for letter writing, the individual must be aware of rules of style and format, take into account the needs of the reader, and plan and organize a sentence or message into comprehensible order. Assessment of the context in which literacy skills are used (or not used) may improve our knowledge of how literacy influences performance on measures of abstraction, comprehension, and problem solving. If cultural and individual factors can mediate the relationship between literacy and cognitive ability, the effect on neuropsychological test performance may not be straightforward or universal.

Given that elders are more likely to have low literacy skills, dementia assessments must include measures that are minimally sensitive to literacy status or have adequate literacy-based norms. Our results suggest that two measures, verbal recall and category fluency, are unaffected by literacy status. However, a great deal of research is still required in order to clarify the nature of the effect of literacy on cognitive test performance.

\section{ACKNOWLEDGMENTS}

This research was supported by federal Grants AG07232 (R. Mayeux), AG08702 (R. Mayeux) and the Taub Center for Alzheimer's Disease Research in the City of New York. Partial data from this paper were presented at the 26th Annual Meeting of the International Neuropsychological Society in Honolulu, Hawaii. The authors thank Rosann Costa for her help with data management and Maria Gonzalez-Diaz for her assistance with scheduling participants.

\section{REFERENCES}

American Psychiatric Association. (1987). Diagnostic and Statistical Manual of Mental Disorders, Revised Third Edition. Washington, DC: American Psychiatric Press Inc.

Ardila, A., Rosselli, M., \& Rosas, P. (1989). Neuropsychological assessment in illiterates: Visuospatial and memory abilities. Brain and Cognition, 11, 147-166.

Barr, A. \& Brandt, J. (1996). Word-list generation deficits in dementia. Journal of Clinical and Experimental Neuropsychology, 18, 810-822.
Benton, A.L. (1955). The Visual Retention Test. New York: The Psychological Corporation.

Benton, A.L. \& Hamsher, K.D. (1976). Multilingual Aphasia Examination. Iowa City, IA: University of Iowa.

Berkman, L.F. (1986). The association between educational attainment and mental status examinations: Of etiologic significance for senile dementias or not? Journal of Chronic Diseases, 39 , 171-174.

Binetti, G., Magni, E., Cappa, S.F., Padovani, A., Bianchetti, A., \& Trabucchi, M. (1995). Semantic memory in Alzheimer's disease: An analysis of category fluency. Journal of Clinical and Experimental Neuropsychology, 17, 82-89.

Blessed, G., Tomlinson, B.E., \& Roth, M. (1968). The association between quantitative measures of senile change in the cerebral grey matter of elderly subjects. British Journal of Psychology, 114, 797-811.

Boller, F., Mizutani, T., Roessmann, U., \& Gambetti, P. (1980). Parkinson's disease, dementia, and Alzheimer's disease: Clinicopathological correlations. Annals of Neurology, 1, 329-335.

Bonaiuto, S., Rocca, W.A., Lippi, A., Luciani, P., Turtù, F., Cavarzeran, F., \& Amaducci, L. (1990). Impact of education and occupation on prevalence of Alzheimer's disease (AD) and multi-infarct dementia (MID) in Appignano, Macerata Province, Italy. Neurology, 40 (Suppl. 1), 346 [Abstract].

Bondi, M.W., Salmon, D.P., \& Butters, N. (1994). Neuropsychological features of memory disorders in Alzheimer's disease. In R.D. Terry, R. Katzman, \& K.L. Bick (Eds.), Alzheimer's disease (pp. 41-63). New York: Raven Press.

Buschke, H. \& Fuld, P.A. (1974). Evaluating storage, retention, and retrieval in disordered memory and learning. Neurology, 24, 1019-1025.

Dartigues, J.F., Gagnon, M., Michel, P., Letenneur, L., Commenges, D., Barberger-Gateau, P., Auriacombe, S., Rigal, B., Bedry, R., Alperovitch, A., Orgogozo, J.M., Henry, P., Loiseau, P., Salamon, R., et Groupe d'Étude Paquid. (1991). Le programme de recherche paquid sur l'epidemiologie de la demence methodes et resultats initiaux. Revue Neurologique [Neurological Review], 147, 225-230.

Evans, D.A., Beckett, L.A., Albert, M.S., Hebert, L.E., Scherr, P.A., Funkenstein, H.H., \& Taylor, J.O. (1993). Level of education and change in cognitive function in a community population of older persons. Annals of Epidemiology, 3, 71-77.

Finley, G.E., Ardila, A., \& Rosselli, M. (1991). Cognitive aging in illiterate Colombian adults: A reversal of the classical aging pattern? Revista Interamericana de Psicologia, 25, 103-105.

Folstein, M.F., Folstein, S.E., \& McHugh, P.R. (1975). 'Minimental State': A practical method for grading the cognitive state of patients for the clinician. Journal of Psychiatric Research, 12, 189-198.

Fratiglioni, L., Grut, M., Forsell, Y., Viitanen, M., Grafstrom, M., Holmen, K., Ericsson, K., Backman, L., Ahlbom, A., \& Winblad, B. (1991). Prevalence of Alzheimer's disease and other dementias in an elderly urban population: Relationship with age, sex and education. Neurology, 41, 1886-1892.

Friedland, R. (1993). Epidemiology, education, and the ecology of Alzheimer's disease. Neurology, 43, 13-20.

Goodglass, H. \& Kaplan, E. (1983). The assessment of aphasia and related disorders. (2nd ed.). Philadelphia: Lea \& Febiger.

Gurland, B.J. (1981). The borderlands of dementia: The influence of sociocultural characteristics on rates of dementia occurring in the senium. In N.E. Miller \& G.D. Cohen (Eds.), Clinical 
aspects of Alzheimer's disease and senile dementia (pp. 6184). New York: Raven Press.

Heaton, R.K., Grant, I., \& Matthews, C.G. (1986). Differences in neuropsychological test performance associated with age, education, and sex. In I. Grant \& K.M. Adams (Eds.), Neuropsychological assessment of neuropsychiatric disorders (pp. 100120). New York: Oxford University Press.

Jacobs, D.M., Sano, M., Albert, S., Schofield, P., Dooneief, G., \& Stern, Y. (1997). Cross-cultural neuropsychological assessment: A comparison of randomly selected, demographically matched cohorts of English- and Spanish-speaking older adults. Journal of Clinical and Experimental Neuropsychology, 19, 331-339.

Kaplan, E., Goodglass, H., \& Weintraub, S. (1983). Boston Naming Test. Philadelphia: Lea \& Febiger.

Katzman, R. (1993). Education and the prevalence of dementia and Alzheimer's disease. Neurology, 43, 13-20.

Katzman, R., Brown, T., \& Fuld, P. (1983). Validation of a short orientation-memory-concentration test of cognitive impairment. American Journal of Psychiatry, 140, 734-738.

Katzman, R., Zhang, M., Qu, O.Y., Wang, Z., Liu, W.T., Yu, E., Wong, S.C., Salmon, D.P., \& Grant, I. (1988). A Chinese version of the Mini-Mental State Examination: Impact of illiteracy in a Shanghai dementia survey. Journal of Clinical Epidemiology, 41, 971-978.

Kirsch, I.S., Jungeblut, A., Jenkins, L., \& Kolstad, A. (1993). Adult literacy in America: The National Adult Literacy Survey. National Center for Education Statistics, US Department of Education. Washington, DC: U.S. Government Printing Office.

Kittner, S.J., White, L.R., Farmer, M.E., Wolz, M., Kaplan, E., Moes, E., Brody, J.A., \& Feinleib, M. (1997). Methodological issues in screening for dementia: The problem of education adjustment. Journal of Chronic Diseases, 39, 163-170.

Korczyn, A.D., Kahana, E., \& Galper, Y. (1991). Epidemiology of dementia in Ashkelon, Israel. Neuroepidemiology, 10, 100 [Abstract].

Lecours, A.R., Mehler, J., \& Parente, M.A. (1988). Illiteracy and brain damage. 3. A contribution to the study of speech and language disorders in illiterates with unilateral brain damage (initial testing). Neuropsychologia, 26, 575-589.

Lecours, A.R., Mehler, J., Parente, M.A., Caldeira, A., Cary, L., Castro, M.J., Dehaut, F., Delgado, R., Gurd, J., Karmann, D.F., Jakubovitz, R., Osorio, Z., Cabral, L.S., \& Junquerira, A.M.S. (1987). Illiteracy and brain damage. 1. Aphasia testing in culturally contrasted populations (control subjects). Neuropsychologia, 25, 231-245.

Luria, A.R. (1976). Cognitive development, its cultural and social foundations. Cambridge, MA: Harvard University Press.

Manly, J.J., Jacobs, D.M., Sano, M., Bell, K., Merchant, C.A., Small, S.A., \& Stern, Y. (1998). Cognitive test performance among nondemented elderly African Americans and Whites. Neurology, 50, 1238-1245.

Mattis, S. (1976). Mental status examination for organic mental syndrome in the elderly patient. In L. Bellak \& T. B. Karasu (Eds.), Geriatric psychiatry (pp. 77-121). New York: Grune \& Stratton.

Matute, E., Leal, F., Zaraboso, A., Robles, A., \& Cedillo, C. (1997). Influence of literacy level on stick constructions in non-braindamaged subjects. Journal of the International Neuropsychological Society, 3, 32 [Abstract].

Monsch, A.U., Bondi, M.W., Butters, N., Salmon, D., Katzman, R., \& Thal, L. (1992). Comparisons of verbal fluency tasks in the detection of dementia of the Alzheimer type. Archives of Neurology, 49, 1253-1258.

Monsch, A.U., Seifritz, E., Taylor, K.I., Ermini-Funfschilling, D., Stahelin, H.B., \& Speigel, R. (1997). Category fluency is also predominately affected in Swiss Alzheimer's disease patients. Acta Neurologica Scandinavica, 95, 81-84.

Mortimer, J.A. (1988). Do psychosocial risk factors contribute to Alzheimer's disease. In A.S. Henderson \& J.H. Henderson (Eds.), Etiology of dementia of Alzheimer's type (pp. 39-52). Chichester, U.K.: John Wiley \& Sons.

Reis, A. \& Castro-Caldas, A. (1997). Illiteracy: A cause for biased cognitive development. Journal of the International Neuropsychological Society, 3, 444-450.

Reis, A., Guerreiro, M., \& Castro-Caldas, A. (1994). Influence of educational level of non brain-damaged subjects on visual naming capacities. Journal of Clinical and Experimental Neuropsychology, 16, 939-942.

Rocca, W.A., Hofman, A., Brayne, C., Breteler, M.M., Clarke, M., Copeland, J.R., Dartigues, J.F., Engedal, K., Hagnell, O., Heeren, T.J., Jonker, C., Lindesay, J., Lobo, A., Mann, A., Molsa, P.K., Morgan, K., O’Connor, D.W., da Silva Droux, A., Sulkava, R., \& Kay, D.W. (1991). The prevalence of vascular dementia in Europe: Facts and fragments from 1980-1990 studies. Annals of Neurology, 30, 817-824.

Rosen, W. (1981). The Rosen Drawing Test. Bronx, NY: Veterans Administration Medical Center.

Rosselli, M., Ardila, A., \& Rosas, P. (1990). Neuropsychological assessment in illiterates. II. Language and praxic abilities. Brain and Cognition, 12, 281-296.

Satz, P. (1993). Brain reserve capacity on symptom onset after brain injury: A formulation and review of evidence for threshold theory. Neuropsychology, 7, 273-295.

Scribner, S. \& Cole, M. (1981). The psychology of literacy. Cambridge, MA: Harvard University Press.

Snowdon, D.A., Kemper, S.J., Mortimer, J.A., Greiner, L.H., Wekstein, D.R., \& Markesbery, W.R. (1996). Linguistic ability in early life and cognitive function and Alzheimer's disease in late life. Findings from the Nun Study. Journal of the American Medical Association, 275, 528-532.

SPSS Inc. (1993). SPSS for Windows, Release 6.0 manual. Chicago: Author.

Stern, Y., Alexander, G.E., Prohovnik, I., \& Mayeux, R. (1992a). Inverse relationship between education and parietotemporal perfusion deficit in Alzheimer's disease. Annals of Neurology, 32, 371-375

Stern, Y., Alexander, G.E., Prohovnik, I., Stricks, L., Link, B., Lennon, M.C., \& Mayeux, R. (1995). Relationship between lifetime occupation and parietal flow: Implications for a reserve against Alzheimer's disease pathology. Neurology, 45, 55-60.

Stern, Y., Andrews, H., Pittman, J., Sano, M., Tatemichi, T., Lantigua, R., \& Mayeux, R. (1992b). Diagnosis of dementia in a heterogeneous population. Development of a neuropsychological paradigm-based diagnosis of dementia and quantified correction for the effects of education. Archives of Neurology, 49, 453-460.

Stern, Y., Stricks, L., Alexander, G., Prohovnik, I., \& Mayeux, R. (1992c). Relationship between occupational demands and parietotemporal perfusion in Alzheimer's disease. Annals of Neurology, 32, 270 [Abstract].

Tröster, A.I., Butters, N., Salmon, D.P., Cullum, C.M., Jacobs, D., Brandt, J., \& White, R.F. (1993). The diagnostic utility of savings scores: Differentiating Alzheimer's and Huntington's dis- 
eases with the Logical Memory and Visual Reproduction tests. Journal of Clinical and Experimental Neuropsychology, 15, 773-788.

Tröster, A.I., Salmon, D.P., McCullough, D., \& Butters, N. (1989). A comparison of the category fluency deficits associated with Alzheimer's and Huntington's disease. Brain and Language, 37, 500-513.

UNESCO Department of Statistics. (1997) [Internet]. Table 1.3: Illiterate population 15 years and over and percentage illiteracy, by age group. Available: http://unesco.uneb.edu/educprog/ stat/spreadsheets/yb_01_03.html

Vygotsky, L.S. (1962). Thought and language. Cambridge, MA: MIT Press.

Vygotsky, L.S. (1978). Mind in society: The development of higher psychological processes. Cambridge, MA: Harvard University Press.

Wechsler, D. (1981). Wechsler Adult Intelligence Scale-Revised. New York: The Psychological Corporation.
Wechsler, D. (1997). Wechsler Adult Intelligence Scale, Third Edition. San Antonio, TX: The Psychological Corporation.

Weiss, B.D., Reed, R.L., \& Kligman, E.W. (1995a). Literacy skills and communication methods of low-income older persons. $\mathrm{Pa}$ tient Education and Counseling, 25, 109-119.

Weiss, B.D., Reed, R.L., Kligman, E.W., \& Abyad, A. (1995b). Literacy and performance on the Mini-Mental State Examination. Journal of the American Geriatric Society, 43, 807-810.

Welsh, K.A., Butters, N., Hughes, J.P., Mohs, R.C., \& Heyman, A. (1992). Detection and staging of dementia in Alzheimer's disease: Use of the neuropsychological measures developed for the Consortium to Establish a Registry for Alzheimer's Disease. Archives of Neurology, 49, 448-452.

Zhang, M., Katzman, R., Salmon, D., Jin, H., Cai, G., Wang, Z., Qu, G., Grant, I., Yu, E., Levy, P., Klauber, M.R., \& Liu, W.T. (1990). The prevalence of dementia and Alzheimer's disease in Shanghai, China: Impact of age, gender and education. Annals of Neurology, 27, 428-437. 